\title{
ANALISA KINERJA MESIN ROUGHING STAND DENGAN MENGGUNAKAN METODE OVERALL EQUIPMENT EFFECTIVENESS (OEE) DAN FAILURE MODE EFFECT ANALYSIS (FMEA)
}

\author{
Hasrul Hasrul, M. Jihan Shofa, Heru Winarno \\ Program Studi Teknik Industri, Fakultas Teknik, Universitas Serang Raya \\ Email: acungj199@gmail.com; m.j.shofa@gmail.com; heruwinarno42@yahoo.co.id
}

\begin{abstract}
Abstrak -Mesin roughing stand berfungsi untuk pembentukan baja/produk, dan roll tersebut memiliki 5 stand, dan dari setiap stand tersebut memiliki roll yang berbeda-beda. Dalam proses produksinya mesin ini juga mengalami kendala-kendala yang menghambat proses[ produksi. Penelitian ini bertujuan untuk mengetahui nilai Overall Equipment Effectiveness (OEE) dan analisa penyebab nilai OEE belum maksimal berdasarkan analisa Failure Mode and Effect Analysis (FMEA). Data yang digunakan adalah data historis mesin roughing stand selama bulan juli 2016-desember 2016. Berdasarkan pengolahan data yang dilakukan diperoleh hasil nilai Overall Equipment Effectiveness (OEE) pada mesin Roughing Stand diperoleh sebesar 57,5. Prioritas potensi kegagalan berdasarkan urutan nilai Risk Priority Number (RPN), didapatkan item screw up tidak bekerja memiliki nilai RPN terbesar (56). Pemberian pelumasan secara berkala merupakan salah satu cara untuk memaksimalkan kinerja screw up.
\end{abstract}

Kata kunci: Failure Mode and Effect Analysis; Mesin Roughing Stand; Overall Equipment Effectiveness

\begin{abstract}
The roughing stand machine functions for steel/product formation and the roll has five stands, and from each position has a different turn. In the production process, this machine also experiences obstacles that hinder the process [of production]. This study aims to determine the value of Overall Equipment Effectiveness (OEE) and analysis of the causes of OEE values have not been maximized based on the review of Failure Mode and Effect Analysis (FMEA). The data used are historical data of roughing stand machines during July 2016-December 2016. Based on the data processing performed, the results of the Overall Equipment Effectiveness (OEE) obtained on the Roughing Stand machine purchased at 57.5. The potential failure priority is base on the order of Risk Priority Number (RPN), the screw up non-working item has the most considerable RPN value (56). Regular lubrication is one way to maximize screw up performance..
\end{abstract}

Keywords: Failure Mode and Effect Analysis; Overall Equipment Effectiveness; Roughing Stand Machine

\section{PENDAHULUAN}

Perkembangan hasil industri yang semakin meningkat secara terus-menerus memerlukan dukungan proses produksi yang lancar. Dalam hal ini pihak perusahaan menginginkan agar peralatan produksinya tetap berada dalam kondisi yang baik sehingga dapat beroperasi secara memuaskan. Untuk menjaga kondisi dari mesin-mesin tersebut agar berada dalam keadaan yang optimal saat digunakan, maka diperlukan kegiatan perawatan pada mesinmesin tersebut untuk menjaga keandalan sistem dan menyediakan mesin cadangan untuk menghindari menurunnya availabilitas sistem karena tindakan pemeliharaan (Adianto, Sitompul, \& Susana, 2005).

Mesin merupakan salah satu alat produksi yang mempunyai peranan yang sangat penting dalam produktivitas dalam suatu perusahaan (Pujotomo \& Kartha, 2007). Kelancaran dari pelaksanaan proses produksi merupakan suatu hal pokok yang harus dicapai. Salah satu fungsi yang memegang peranan yang sangat penting dalam menjamin kelancaran pelaksanaan kegiatan produksi adalah perawatan mesin dan fasilitas produksi lainnya. Oleh sebab itu, suatu perusahaan harus selalu mengusahakan mesin dan fasilitas dalam kondisi yang terbaik sehingga proses produksi dapat berjalan dengan lancar. 
Total Productive Maintenance (TPM) merupakan salah satu metode yang menjadi acuan dalam mengevaluasi kinerja suatu peralatan. TPM merupakan pengembangan model perawatan untuk meningkatkan produktivitas mesin dalam menunjang proses produksi (Ahuja \& Khamba, 2008; Nakajima, 1988, 1989). TPM mempunyai tujuan untuk menjaga mesin berada dalam kondisi prima sehingga tidak mengganggu proses produksi (Limantoro, 2013).

Overall Equipment Effectiveness (OEE) merupakan ukuran keberhasilan yang digunakan metode TPM. OEE merupakan perbandingan rasio dari output aktual dengan output maksimal peralatan (Nakajima, 1988). Hasil perhitungan OEE dapat digunakan untuk mengevaluasi kinerja peralatan perusahaan sebagai dasar perbaikan yang diperlukan untuk meningkatkan kinerja peralatan tersebut (Muchiri \& Pintelon, 2008; Rinawati \& Dewi, 2014).

Mesin roughing stand pada perusahaan yang memproduksi baja berfungsi untuk pembentukan baja/produk, dan roll tersebut memiliki 5 stand, dan dari setiap stand tersebut memiliki roll yang berbeda-beda. Pada kesehariannya mesin ini tidak luput dari permasalahan yang menghambat proses produksi. Jika ini tidak dianalisa dan dievaluasi kinerjanya akan berdampak pada gangguan proses serta meningkatkan biaya produksi.

Penelitian ini bertujuan untuk mengetahui kinerja mesin roughing stand saat ini. Hasil OEE digunakan sebagai dasar penentuan prioritas perbaikan dalam meningkatkan kinerja mesin roughing stand. Upaya perbaikan yang dilakukan dapat menjadi kebijakan perusahaan dalam mengambil keputusan mengenai perencanaan perawatan peralatan yang lebih baik lagi.

\section{METODE PENELITIAN}

Penelitian menggunakan perhitungan Overall Equipment Effectiveness (OEE) berdasarkan data historis selama bulan juli 2016 sampai desember 2016. Langkah selanjutnya adalah menganalisa penyebab nilai OEE belum maksimal berdasarkan analisa Failure Mode and Effect Analysis (FMEA).

Overall Equipment Effectiveness (OEE) digunakan untuk mengidentifikasi dan mengukur faktor kerugian berdasarkan ketersediaan, kinerja dan tingkat kualitas (Wijaya \& Widyadana, 2015). Perhitungan OEE didasarkan pada tiga faktor utama yaitu ketersediaan (availability), kinerja (performance rate), dan kualitas (quality rate).

Availability (Ketersediaan) adalah tingkat pengoperasian suatu mesin atau sistem. Performance efficiency adalah tingkat performa yang ditunjukkan oleh suatu mesin atau sistem dalam menjalankan tugas yang ditetapkan. Rate of quality product (Tingkat Kualitas) adalah rasio produk yang sesuai dengan spesifikasi kualitas produk yang telah ditentukan terhadap jumlah produk yang diproses. Dengan menggunakan perhitungan Overall Equipment Effectiveness (OEE) akan diketahui ukuran tingkatan efisiensi dan produktivitas pada suatu mesin. Data yang dibutuhkan berupa data waktu downtime, planned downtime, data waktu setup, dan data waktu produksi.

Availability $=\frac{\text { Total time available-downtime }}{\text { Total time available }} \times 100 \%$

Performance $=\frac{\text { Total Production }}{\text { Possible total production }} \times 100 \%$

Possible total production $=$ total production + $\left(\frac{\text { downtime }}{\text { cycle time }+ \text { set up }}\right) x$ one time production

Quality $=\frac{\text { Total production-Total Defect }}{\text { Total production }} \times 100 \%$

OEE = Availability $\times$ Performance $\times$ Quality $\times$ $100 \%$

FMEA (Failure Mode and Effect Analysis) dipergunakan setelah mendapatkan faktor yang mempengaruhi kegagalan atau kecacatan dengan tujuan didapatkan faktor mana yang memerlukan penanganan lebih lanjut. Dengan melihat analisa FMEA, dapat diketahui penyebab potensial yang memerlukan tindakan perbaikan segera. Nilai RPN didapat dari hasil perkalian nilai SOD (Severity Occurrence Detection),

Severity adalah langkah pertama untuk menganalisa resiko, yaitu menghitung seberapa besar dampak atau intensitas kejadian mempengaruhi hasil akhir proses. Dampak tersebut di rating mulai 1 sampai 10, dimana 10 merupakan dampak terburuk (tabel 1). Detection berfungsi untuk upaya pencegahan terhadap proses produksi dan mengurangi tingkat kegagalan pada proses produksi (tabel 2). Occurrence merupakan kemungkinan bahwa penyebab kegagalan akan terjadi dan menghasilkan bentuk kegagalan selama masa produksi produk (Tabel 3)

Setelah mendapatkan nilai severity, occurrence, dan detection pada perbaikan terhadap mesin roughing stand, maka akan diperoleh nilai RPN dengan cara mengkalikan severity, occurrence, dan detection (RPN=SxOxD) yang kemudian dilakukan pengurutan berdasarkan nilai RPN tertinggi 
sampai yang terendah. Setelah itu, kegiatan perbaikan yang mempunyai nilai RPN besar dan mempunyai peranan penting dalam suatu kegiatan produksi, dilakukan usulan perbaikan untuk menurunkan tingkat perbaikan mesin.

Tabel 1. Nilai Severity

\begin{tabular}{|c|c|}
\hline Rating & Criteria of severity effect \\
\hline 1 & Tidak ada efek \\
\hline 2 & Tidak terdapat efek dan pekerja tidak menyadari adanya masalah \\
\hline 3 & Tidak terdapat efek dan pekerja menyadari adanya masalah \\
\hline 4 & $\begin{array}{l}\text { Perubahan fungsi dan banyak pekerja menyadari adanya } \\
\text { perubahan }\end{array}$ \\
\hline 5 & Mengurangi kenyamanan fungsi penggunaan \\
\hline 6 & Kehilangan kenyamanan fungsi penggunaan \\
\hline 7 & Pengurangan fungsi utama \\
\hline 8 & Kehilangan fungsi utama \\
\hline 9 & Kehilangan fungsi utama dan menimbulkan peringatan \\
\hline 10 & Tidak berfungsi sama sekali \\
\hline
\end{tabular}

Tabel 2. Nilai Occurrence

\begin{tabular}{cl}
\hline Rating & \multicolumn{1}{c}{ Probability of occurrence } \\
\hline 1 & Tidak pernah sama sekali \\
2 & Lebih kecil dari 5 per 7200 jam penggunaan \\
3 & $5-10$ per 7200 jam penggunaan \\
4 & $11-15$ per 7200 jam penggunaan \\
5 & $15-20$ per 7200 jam penggunaan \\
6 & $21-25$ per 7200 jam penggunaan \\
7 & 26-30 per 7200 jam penggunaan \\
8 & 31-35 per 7200 jam penggunaan \\
9 & 36-40 per 7200 jam penggunaan \\
10 & Lebih besar dari 50 nper 7200 jam penggunaan \\
\hline
\end{tabular}

Tabel 3. Nilai Detection

\begin{tabular}{cl}
\hline Rating & \multicolumn{1}{c}{ Detection design control } \\
\hline 1 & Pasti terdeteksi \\
2 & Kesempatan yang sangat tinggi untuk terdeteksi \\
3 & Kesempatan yang tinggi untuk terdeteksi \\
4 & Kesempatan yang cukup tinggi untuk terdeteksi \\
5 & Kesempatan yang sedang untuk terdeteksi \\
6 & Kesempatan yang rendah untu terdeteksi \\
7 & Kesempatan yang sangat rendah untuk terdeteksi \\
8 & Kesempatan yang sangat rendah dan sulit untuk terdeteksi \\
9 & Kesempatan yang sangat rendah dan sangat sulit untuk terdeteksi \\
10 & Tidak mampu terdeteksi \\
\hline
\end{tabular}




\section{HASIL DAN PEMBAHASAN}

Data yang digunakan pada penelitian ini berdasarkan data historis yang ada pada database perusahaan yang berupa . data utilisasi diantaranya breakdown, oprating time dan data output dari mesin Roughing Stand seperti total produksi, good products dan data defect pada periode 2016 (Tabel 1). Data tersebut digunakan untuk perhitungan Overall Equipment Effectiveness (OEE).

Tabel 1.Data Mesin Roughing Juli 2016-Desember 2016

\begin{tabular}{llllllll}
\hline Bulan & $\begin{array}{c}\text { Total Waktu } \\
\text { Kerusakan } \\
\text { (Menit) }\end{array}$ & $\begin{array}{c}\text { Total Waktu } \\
\text { Pemeliharaan } \\
\text { (Menit) }\end{array}$ & $\begin{array}{c}\text { Total } \\
\text { Waktu Set } \\
\text { Up (Jam) }\end{array}$ & $\begin{array}{c}\text { Total } \\
\text { Availability } \\
\text { (Jam) }\end{array}$ & $\begin{array}{c}\text { Total Good } \\
\text { Product } \\
\text { (Ton) }\end{array}$ & $\begin{array}{c}\text { Target } \\
\text { Produksi } \\
\text { (Ton) }\end{array}$ & $\begin{array}{c}\text { Total } \\
\text { Reject } \\
\text { (Ton) }\end{array}$ \\
\hline Juli & 30 & 25 & 18,56 & 480 & $3.965,91$ & 8.000 & 92,22 \\
Agustus & 255 & 250 & 46,24 & 480 & $4.735,61$ & 8.000 & 168,91 \\
September & 120 & 115 & 20,64 & 480 & $5.509,14$ & 8.000 & 134,40 \\
Oktober & 570 & 565 & 59,39 & 480 & $4.385,71$ & 8.000 & 159,74 \\
November & 80 & 75 & 10,92 & 480 & $3.539,07$ & 8.000 & 96,44 \\
Desember & 4.420 & 4.415 & 36,72 & 480 & $6.229,98$ & 8.000 & 128,79 \\
\hline Total & 6.715 & 6.685 & 192,47 & 2.880 & $28.356,42$ & 48.000 & 780,5 \\
\hline
\end{tabular}

Setelah semua data dikumpulkan, selanjutnya dilakukan pengolahan data, formula matematis dari Overall Equipment Effectiveness (OEE). Berdasarkan hasil perhitungan OEE yang telah dilakukan diperoleh hasil rata-rata nilai OEE sebesar $57,5 \%$ dimana nilai tersebut banyak disebabkan faktor performance dan availability terutama di bulan desember (Tabel 4). Langkah selanjutnya adalah mengidentifikasi penyebab nilai OEE yang belum mencapai $85 \%$ berdasarkan faktor downtime yang menjadi salah satu penyebab utama nilai OEE tidak tercapai (Tabel 5).

Tabel 4. Nilai OEE Mesin Roughing Stand

\begin{tabular}{lcccc}
\hline \multicolumn{1}{c}{ Bulan } & Availability & Performance & Quality & OEE \\
\hline Juli & $99 \%$ & $91 \%$ & $97 \%$ & $87 \%$ \\
Agustus & $97 \%$ & $64 \%$ & $96 \%$ & $59 \%$ \\
September & $99 \%$ & $82 \%$ & $97 \%$ & $78 \%$ \\
Oktober & $95 \%$ & $44 \%$ & $96 \%$ & $40 \%$ \\
November & $98 \%$ & $78 \%$ & $97 \%$ & $74 \%$ \\
Desember & $66 \%$ & $11 \%$ & $98 \%$ & $07 \%$ \\
\hline Total & $92,33 \%$ & $61,66 \%$ & $96,83 \%$ & $57,5 \%$ \\
\hline
\end{tabular}

Tabel 5. Jenis Downtime Mesin Roughing Stand

\begin{tabular}{lcc}
\hline Downtime Mesin Roughing & $\begin{array}{c}\text { Waktu } \\
\text { (Menit) }\end{array}$ & Persentase \\
\hline Coupling Reducer Rusak & 4420 & $78 \%$ \\
Bolt Coupling Kendor & 510 & $9 \%$ \\
Bolt Cover Lepas/Patah & 255 & $4 \%$ \\
Manipulator Tidak di Passnya & 235 & $4 \%$ \\
Screw Edger Macet & 180 & $3 \%$ \\
\hline Total & 5600 & 100 \\
\hline
\end{tabular}


Berdasarkan pengurutan nilai downtime dan diagram diatas, didapatkan coupling reducer rusak, bolt coupling kendor, bolt cover lepas/patah, manipulator tidak di passnya, dan screw edger macet. Dari hasil tersebut yang mempunyai nilai downtime tertinggi adalah coupling reducer rusak, maka akan ditindak lanjuti analisis dengan FMEA.

Berdasarkan pengurutan nilai RPN dan berdasarkan tabel diatas, target posisi screw up tidak tercapai, motor trip/macet, gap/celah rolling tidak stabil, screw up tidak bekerja. Dari hasil tersebut yang mempunyai nilai Risk Priority
Number (RPN) tertinggi adalah screw up tidak bekerja. Hal ini menandakan terdapat mode kegagalan yang harus dilakukan perbaikan. Perbaikan yang akan dilakukan tersebut berdasarkan penyebab-penyebab kegagalan yang telah di analisis berdasarkan Failure Mode and Effect Analysis (FMEA) sehingga diketahui permasalahan yang terjadi untuk dilakukan perbaikan. Nilai RPN dari yang terkecil hingga yang paling tinggi yaitu, Target posisi screw up tidak tercapai 12, motor trip/macet 32, gap/celah rolling tidak stabil 36 , dan screw up tidak bekerja 56 (Tabel 6).

Tabel 6. Failure Mode and Effect Analysis

\begin{tabular}{|c|c|c|c|c|c|c|c|}
\hline Kegagalan & $\begin{array}{c}\text { Efek Dari Potensi } \\
\text { Kegagalan }\end{array}$ & $S$ & Potensi Penyebab & $\mathrm{O}$ & Kontrol & $D$ & RPN \\
\hline \multirow{4}{*}{$\begin{array}{c}\text { Coupling } \\
\text { Reducer Rusak }\end{array}$} & $\begin{array}{l}\text { Target posisi Screw } \\
\text { Up tidak tercapai }\end{array}$ & 4 & $\begin{array}{l}\text { Baut coupling } \\
\text { kendor }\end{array}$ & 3 & $\begin{array}{l}\text { Pengencangan baut } \\
\text { coupling }\end{array}$ & 1 & 12 \\
\hline & Motor trip / macet & 4 & $\begin{array}{l}\text { Beban screw up } \\
\text { berlebih }\end{array}$ & 4 & $\begin{array}{l}\text { Seting ulang } \\
\text { alignment posisi } \\
\text { motor }\end{array}$ & 2 & 32 \\
\hline & $\begin{array}{l}\text { Gap/celah rolling } \\
\text { tidak stabil }\end{array}$ & 6 & Karena baut patah & 3 & Penggantian baut & 2 & 36 \\
\hline & $\begin{array}{l}\text { Screw up tidak } \\
\text { bekerja }\end{array}$ & 7 & $\begin{array}{l}\text { Gear coupling } \\
\text { rontok / gear aus }\end{array}$ & 4 & $\begin{array}{l}\text { Pembersihan / } \\
\text { penambahan } \\
\text { pelumas }\end{array}$ & 2 & 56 \\
\hline
\end{tabular}

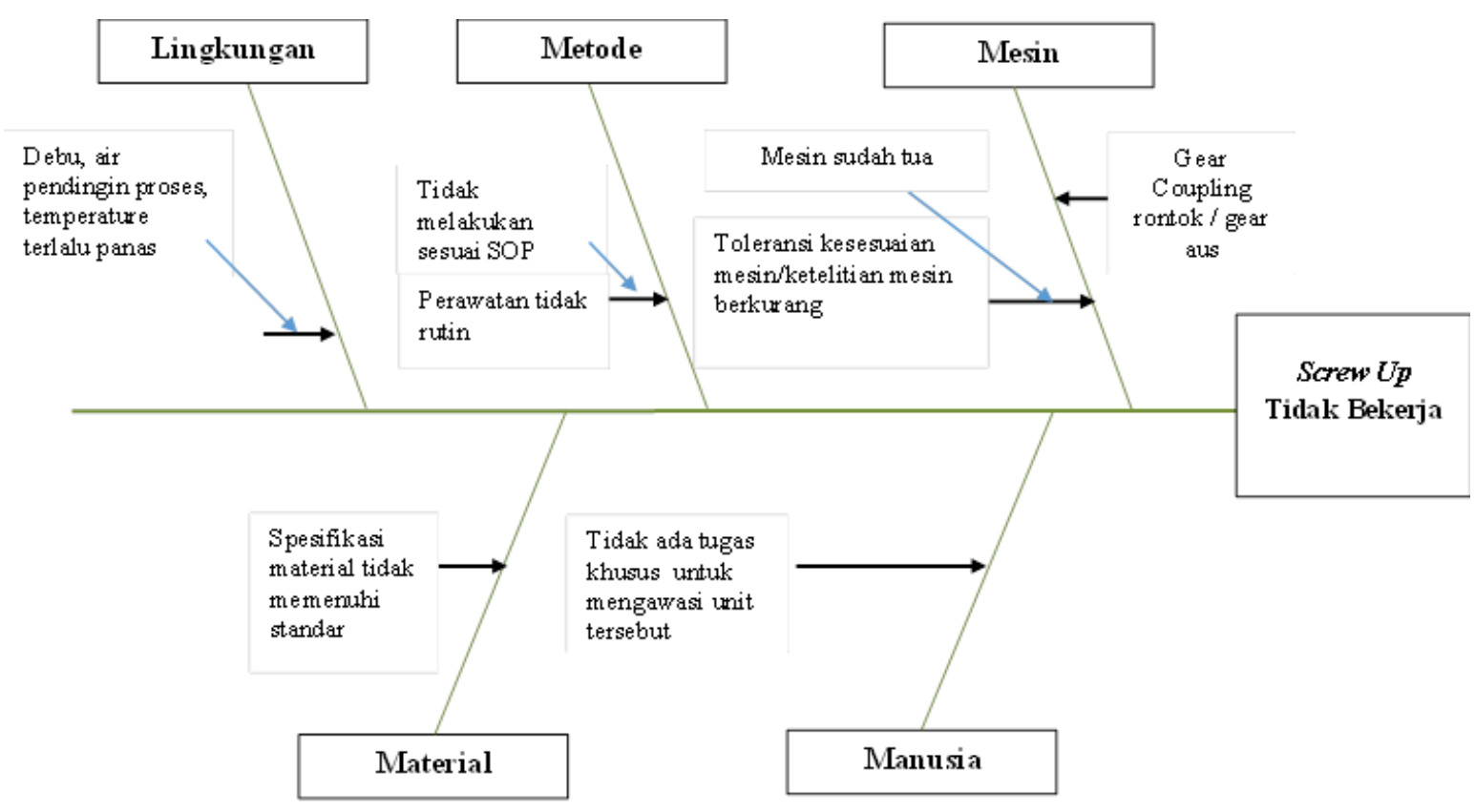

Gambar 1. Fishbone Diagram 
Berdasarkan diagram sebab akibat (Gambar 1), diketahui bahwa 5 kategori yang dapat dianalisis dengan Failure Mode and Effect Analysis (FMEA) sebagai penyebab Screw up tidak bekerja yaitu dari faktor lingkungan, metode, manusia, mesin, material. Untuk kategori manusia, perusahaan sudah memilih karyawan dengan benar hanya saja perlu pelatihan lagi agar lebih teliti ketika sedang perbaikan cara penggunaan alat ketika pemasangan dan harus adanya petugas khusus untuk mengawasi unit/mesin tersebut.Untuk kategori metode perawatan belum terlaksana dengan baik. Untuk kategori lingkungan hendaknya seluruh karyawan untuk menjaga kebersihan agar tidak menjadi masalah. Untuk kategori material harus menggunakan material yang sesuai dengan standar yang telah ditentukan, agar tidak terjadi hal yang tidak diinginkan. Dan untuk kategori mesin karena usia mesin yang sudah tidak muda, bisa mengakibatkan problem. Untuk kategori lingkungan harus selalu diperiksa kebersihannya sehingga tidak menimbulkan penyebab adanya terjadinya screw up tidak bekerja.

\section{KESIMPULAN}

Berdasarkan hasil analisis yang telah dilakukan diperoleh bahwa nilai Overall Equipment Effectiveness (OEE) pada mesin Roughing Stand diperoleh sebesar 57,5. Prioritas potensi kegagalan berdasarkan urutan nilai Risk Priority Number (RPN), didapatkan item screw up tidak bekerja memiliki nilai RPN terbesar (56) dengan penyebab debu, air pendingin proses, temperatur terlalu panas dan area kurang bersih. Untuk kategori metode tidak melakukan sesuai SOP sehingga tindakan perawatan tidak rutin, untuk mesin toleransi kesesuaian mesin/ketelitian mesin berkurang dikarenakan mesin sudah tua, gear coupling rontok / gear aus, dari segi material spesifikasi material tidak memenuhi standar, dan dari manusianya tidak ada tugas khusus untuk mengawasi unit tersebut.

\section{DAFTAR PUSTAKA}

Adianto, H., Sitompul, C., \& Susana, S. (2005). Penerapan Model Preventive Maintenance Smith dan Dekker di PD. Industri Unit Inkaba. Jurnal Teknik Industri, 7(1), 51-60.

Ahuja, I. P. S., \& Khamba, J. S. (2008). Total productive maintenance: literature review and directions. International Journal of Quality \& Reliability Management, 25(7), 709-756.

Limantoro, D. (2013). Total Productive Maintenance di PT. X. Jurnal Titra, 1(1), 13-20.
Muchiri, P., \& Pintelon, L. (2008). Performance measurement using overall equipment effectiveness (OEE): literature review and practical application discussion. International Journal of Production Research, 46(13), 3517-3535.

Nakajima, S. (1988). Introduction to TPM: total productive maintenance. Productivity Press, Inc.

Nakajima, S. (1989). TPM development program: implementing total productive maintenance. Productivity press Cambridge.

Pujotomo, D., \& Kartha, R. (2007). Analisa Sistem Perawatan Komponen Bearing Bottom Roller Dan V Belt Mesin Ring Frame Ry-5 Pada Departemen Spinning II a (Di PT Danliris Surakarta). J@ Ti Undip: Jurnal Teknik Industri, 2(2), 40-48.

Rinawati, D. I., \& Dewi, N. C. (2014). Analisis Penerapan Total Productive Maintenance (TPM) Menggunakan Overall Equipment Efectiveness (Oee) Dan Six Big Losses Pada Mesin Cavitec Di PT. Essentra Surabaya. Prosiding SNATIF, 21-26.

Wijaya, C. Y., \& Widyadana, I. G. A. (2015). Pengukuran Overall Equipment Effectiveness (OEE) di PT Astra Otoparts Tbk. Divisi Adiwira Plastik. Jurnal Titra, 3(1), 41-48. 